\title{
Determinação do Potencial Antimicrobiano de Óleos Essenciais de Lavanda (Lavandula Dentata L.) e Manjericão (Ocimum Basilicum L.) Sobre Cepas de Pseudomonas Aeruginosa Isolada de Leite Mastitíco Bovino
}

\author{
Bruna Carolina Ulsenheimer, ${ }^{1}$ Silvana Konageski Dalla Rosa, ${ }^{2}$ Christiane de Fatima Colet, ${ }^{2}$ \\ Luciana Mori Viero, ${ }^{2}$ Luciane Ribeiro Viana Martins ${ }^{2}$
}

\begin{abstract}
RESUMO
Objetivo: Avaliar óleos essenciais extraídos da flor e folha de lavanda (Lavandula dentata L.) e manjericão (Ocimum basilicum L.) quanto à sua ação antimicrobiana ante a bactéria Pseudomonas aeruginosa, isolada de leite mastítico bovino. Método: Foram realizadas coleta, identificação e catalogação das plantas selecionadas, e, após, extração dos óleos essenciais pelo método de arraste a vapor, por hidrodestilação. As análises foram realizadas em triplicata, no Laboratório de Microbiologia Veterinária da Unijuí, pelo cultivo bacteriano em placas, confrontados a $20 \mu \mathrm{l}$ de óleo essencial, mantidas em estufa bacteriológica a 36으 por 24 horas. Resultados: O perfil de sensibilidade antimicrobiana dos óleos essenciais testados diante das cepas de Pseudomonas aeruginosa, apresentou os seguintes resultados: para o óleo essencial da flor do manjericão $7 \mathrm{~mm}$ no tamanho do halo de inibição nos três testes; para a folha do manjericão houve a maior atividade inibitória, com halos de $12 \mathrm{~mm}$ em duas amostras e $14 \mathrm{~mm}$ na terceira. Já para o óleo da flor da lavanda, este apresentou halo de inibição de $6 \mathrm{~mm}$, $7 \mathrm{~mm}$ e $9 \mathrm{~mm}$, em cada teste, e para o óleo da folha da lavanda resultados semelhantes ao da sua flor, com $8 \mathrm{~mm}$ em dois testes e $6 \mathrm{~mm}$ no outro. Conclusões: Sugere-se que o óleo essencial da folha do manjericão possa ser uma fonte de compostos com potencial terapêutico no combate à bactéria patogênica Pseudomonas aeruginosa. Verifica-se que o uso do óleo essencial apresenta-se como uma alternativa para o tratamento de mastites em bovinos leiteiros.
\end{abstract}

Palavras-chave: Mastite. Antibióticos. Óleo essencial. Lavanda. Manjericão.

DETERMINATION OF THE ANTIMICROBIAL POTENTIAL OF LAVANDER ESSENTIAL OILS (LAVANDULA DENTATA L.) AND BASIL (OCIMUM BASILICUM L.) ON STRUCTURES OF PSEUDOMONAS AERUGINOSA DE BOVINO MILK

ABSTRACT

Objective: To evaluate essential oils extracted from the lavender flower and leaf (Lavandula dentata L.) and basil (Ocimum basilicum L.), regarding their antimicrobial action against the bacterium Pseudomonas aeruginosa, isolated from bovine mastitic milk. Method: Collection, identification and cataloging of the selected plants was carried out, and after extraction of essential oils by the method of steam dragging, by hydrodistillation. The analyzes were performed in triplicate, at the Veterinary Microbiology Laboratory of Unijuí, for bacterial culture in plates, compared to $20 \mu \mathrm{l}$ of essential oil, kept in a bacteriological oven at 36 oC for 24 hours. Results: The antimicrobial sensitivity profile of the essential oils tested against the strains of Pseudomonas aeruginosa, presented the following results: for the essential oil of the basil flower $7 \mathrm{~mm}$ in the size of the inhibition halo in the three tests, for the basil leaf, there was the highest inhibitory activity, with $12 \mathrm{~mm}$ halos in two samples and $14 \mathrm{~mm}$ in the third. As for lavender flower oil, it showed an inhibition halo of $6 \mathrm{~mm}, 7 \mathrm{~mm}$ and $9 \mathrm{~mm}$ in each test, and for lavender leaf oil it presented results similar to that of its flower, with $8 \mathrm{~mm}$ in two tests and $6 \mathrm{~mm}$ on the other. Conclusions: It is suggested that the essential oil of the basil leaf may be a source of compounds with therapeutic potential in combating the pathogenic bacteria Pseudomonas aeruginosa. It appears that the use of essential oil is an alternative for the treatment of mastitis in dairy cattle.

Keywords: Mastitis. Antibiotics. Essential oil. Lavender. Basil.

RECEBIDO EM: 4/3/2020

MODIFICAÇÕES SOLICITADAS EM: 26/5/2020

ACEITO EM: 8/6/2020

\footnotetext{
Autora correspondente. Universidade Federal de Santa Maria - UFSM. Av. Roraima, n. 1000, Cidade Universitária, Camobi, Santa Maria/RS, Brasil. 97105-900. http://lattes.cnpq.br/8701658024732179. http://orcid.org/0000-0003-3366-2062. bru.brunna@hotmail.com

${ }_{2}$ Universidade Regional do Noroeste do Estado do Rio Grande do Sul - Unijuí. Ijuí/RS, Brasil.
} 


\section{INTRODUÇÃO}

O Brasil, é considerado um dos maiores produtores mundiais de leite, encontrando-se na quarta posição, com produção anual de 35,1 bilhões de litros de leite no ano de 2017 (EMBRAPA, 2018). Dentro da bovinocultura leiteira, uma das principais doenças encontrada é a mastite bovina, a qual é responsável por causar prejuízos econômicos à cadeia produtiva. A mastite caracteriza-se por um processo inflamatório complexo da glândula mamária que ocorre, na maioria das vezes, em resposta a infecções, sendo $90 \%$ causadas por bactérias e, em menor número, por fungos, algas e vírus (TOZZETTI; BATAIER; ALMEIDA, 2008).

A mastite bovina por Pseudomonas está intimamente relacionada à água contaminada utilizada na lavagem dos tetos, dos insufladores (teteiras), da canalização do equipamento de ordenha, do conteúdo reutilizável de pré ou pós-dipping, ou mesmo em cânulas contaminadas durante a terapia intramamária (SANTOS; FONSECA, 2007).

Bactérias do gênero Pseudomonas são bastonetes aeróbicos gram-negativos que vivem no solo e na água, sendo possível também serem encontradas nas fezes de animais. Embora haja mais de 200 espécies dentro deste gênero, a maioria das doenças é provocada pela Pseudomonas aeruginosa, estando associada em bovinos, principalmente com a ocorrência de mastites (MCVEY; KENNEDY; CHENGAPPA, 2017), e, inclusive, é considerada como a espécie mais patogênica dentro deste gênero (MEGID; RIBEIRO; PAES, 2018).

As doenças infecciosas são uma grande ameaça à saúde humana e animal, sendo responsáveis por elevadas taxas de morbidade e mortalidade. Por esse motivo, o uso de antimicrobianos tem sido utilizado em larga escala, acarretando uma série de problemas, principalmente a resistência microbiana (ANTUNES et al., 2006). Esta problemática da resistência bacteriana aos antibióticos é considerada um dos problemas de saúde pública mais relevantes em âmbito global, dado que apresenta consequências clínicas e econômicas preocupantes, estando associada ao uso inadequado de antibióticos (LOUREIRO et al., 2016 ).

Diante desta problemática, é despertada a perspectiva de uso de outras alternativas que possuam atividade antibacteriana eficiente. Por meio deste conceito, surge a utilização de produtos naturais de plantas bioativas, empregadas com fins preventivos e curativos, sendo uma estratégia promissora e de baixo custo para o controle de infecções (SHER, 2009). As plantas com potencialidades medicinais são capazes de produzir substâncias ativas denominadas metabólitos secun- dários, encontrados em quantidades diminutas no óleo essencial extraído da planta, que apresenta composições químicas variadas e que pode exercer atividades biológicas e farmacológicas importantes (ALVES, 2005).

Os óleos essenciais (OE) são compostos presentes naturalmente em plantas e, consequentemente, exercem funções biológicas relacionadas aos seus mecanismos de defesa. São considerados antimicrobianos naturais e possuem potencial para serem utilizados como alternativas de tratamentos (REIS et al., 2020).

Atualmente têm-se percebido um crescimento exponencial no uso de terapias naturais, com o intuito de tratar várias doenças agudas e crônicas, a qual tem ocorrido de forma paralela ao progresso científico e tecnológico da medicina moderna ocidental (SPADA$\mathrm{ClO}$ et al., 2010). Além de possuir propriedades farmacológicas importantes, os óleos essenciais, quando comparado aos medicamentos, apresentam como vantagem, alta volatilidade e baixo peso molecular de seus componentes, o que possibilita uma rápida eliminação do organismo por meio das vias metabólicas (BANDONI; CZEPAK, 2008). Desta forma, a utilização de produtos naturais como forma de tratamento vem sendo um método alternativo cada vez mais explorado.

O objetivo deste trabalho é analisar o potencial antimicrobiano do óleo essencial extraído da flor e da folha Ocimum basilicum e Landula dentata $L$. ante a bactéria Pseudomonas aeruginosa isolada de leite mastítico bovino.

\section{METODOLOGIA}

\section{Extração do óleo essencial}

As plantas lavanda (Lavandula dentata L.) e manjericão (Ocimum basilicum) foram plantadas na primeira quinzena de dezembro do ano de 2017 na região Noroeste do Estado do Rio Grande do Sul, no município de São José do Inhacorá (Latitude: $27^{\circ} 43^{\prime}$ $39^{\prime \prime}$ Sul, Longitude: $54^{\circ} 7^{\prime} 3^{\prime \prime}$ Oeste.), região que apresenta clima subtropical. Após um período de quatro meses, as plantas apresentaram um desenvolvimento vegetativo e florescente satisfatório e se encontravam em boas condições fitossanitárias. Neste momento foi realizada a colheita destas plantas.

A coleta foi realizada no início do mês de abril de 2018, antes do sol nascer, às $6 \mathrm{~h} 30$ da manhã. Em seguida, amostras das plantas foram encaminhadas para o Laboratório de Botânica da Unijuí para identificação e, posteriormente, catalogação, as quais também receberam números de registro botânico: manjericão, espécie Ocimum basilicum L., HUIRB 7796 e a Lavanda, espécie Lavandula dentata L., HUIRB 7797. 
Após a identificação das plantas, estas foram encaminhadas para o laboratório de química da Unijuí para separação da parte aérea das plantas frescas, das folhas e inflorescências de lavanda e manjericão, realizando a extração de quatro tipos de óleos essenciais.

Para a extração dos óleos foi utilizada a técnica de arraste a vapor, por hidrodestilação, utilizando aparelho graduado tipo Clevenger, com balão volumétrico com capacidade de $2 \mathrm{~L}$, utilizando-se $30 \mathrm{~g}$ de inflorescências, e em outro aparelho $30 \mathrm{~g}$ de folhas, conforme técnica descrita pela Farmacopeia Brasileira (2019). Foram utilizados óleos essenciais da flor da lavanda, folha da lavanda, flor do manjericão e folha do manjericão.

\section{Avaliação antimicrobiana ante à bactéria Pseudomonas aeruginosa isolada de amostras de leite mastítico}

Foi desenvolvido no Laboratório de Microbiologia Veterinária da Unijuí, no período de 2017-2018, exame microbiológico do leite, com amostras de leite mastítico de bovinos, encaminhadas por produtores e Médicos Veterinários da região Noroeste do Estado do Rio Grande do Sul, para o cultivo, identificação bacteriana e análise do perfil de sensibilidade. Após realizadas as análises de cultivo e identificação bacteriana, conforme Zimbro et al. (2009), da bactéria Pseudomonas aeruginosa de amostras de leite, foram utilizadas as cepas bacterianas destas amostras para a realização dos experimentos desenvolvidos que testam a ação antimicrobiana dos óleos essenciais das plantas cultivadas de lavanda e manjericão para o combate de P. aeruginosa.

Para avaliação in vitro da atividade antimicrobiana dos óleos, inicialmente foram dispostos $30 \mathrm{ml}$ de ágar Mueller Hintom em placas de petri estéreis, no qual foi utilizada a técnica de perfuração em ágar, por intermédio da remoção do meio de cultura sólido no centro da placa, realizada com auxílio de um cilindro de $6 \mathrm{~mm}$ de diâmetro para a formação do poço, conforme Ostrosky et al. (2008). Em seguida, as placas permaneceram em estufa bacteriológica a 36Co por 24 horas.

Na próxima etapa foi semeada a bactéria $P$. aeruginosa sobre toda a superfície do ágar, no centro da placa foi disposto $20 \mu \mathrm{l}$ do óleo essencial puro e, em volta deste, foram distribuídos como controle negativo discos imersos em álcool e como controle positivo os discos de antibióticos, ciprofloxacina $(5 \mu \mathrm{g})$, enrofloxacina $(5 \mu \mathrm{g})$, gentamicina $(10 \mu \mathrm{g})$, penicilina (10 UI), sulfazotrim $(25 \mu \mathrm{g})$ e tetraciclina $(30 \mu \mathrm{g})$, quando foi considerada a técnica de antibiograma disco difusão utilizada e o tamanho do halo de inibição dos antibióticos, segundo Kirby e Bauer (2011). Foram, então, mantidas em estufa bacteriológica a 36 ㄷ por 24 horas.

Posteriormente procedeu-se a leitura das placas, com régua milimetrada para a mensuração do tamanho dos halos de inibição do crescimento bacteriano e o perfil de resistência dos antibióticos testados ante a $P$. aeruginosa. Esta avaliação foi realizada em triplicata, para a certificação do experimento. Halos de inibição de crescimento bacteriano dos óleos maiores que $7 \mathrm{~mm}$, foram considerados resultados positivos (NASCIMENTO et al., 2000).

\section{RESULTADOS E DISCUSSÃO}

As colônias de Pseudomonas aeruginosa caracterizam-se por serem grandes com tamanho superior a $1 \mathrm{~mm}$ de diâmetro, de cor cinza metálica e rugosa (MCVEY; KENNEDY; CHENGAPPA, 2017). Inclusive apresentam-se mucoides, iridescentes, irregular e beta-hemolítica, como descrito por Megid, Ribeiro e Paes (2018).

Dentre as bactérias Gram negativas, a $P$. aeruginosa demonstra maior facilidade de desenvolvimento de resistência aos antibióticos (FIGUEIREDO et al., 2007). Neste trabalho, esta bactéria apresentou níveis consideráveis de resistência a três antibióticos, à penicilina, seguido da tetraciclina e sulfazotrim, nos quais apresentaram consecutivamente os seguintes tamanhos de halos de inibição: $0 \mathrm{~mm}$, o que demonstra alta resistência para os antibióticos beta-lactâmicos, e os demais antimicrobianos com $10 \mathrm{~mm}$ e $09 \mathrm{~mm}$. Fernandes et al. (2009), encontraram multirresistência desta bactéria para ampicilina, cefalexina, gentamicina, tetraciclina, penicilina/novobiocina e cloxacilina, demonstrando a necessidade de novas pesquisas que buscam por medidas alternativas de tratamento para infecções causadas pela Pseudomonas aeruginosa.

Foi verificada sensibilidade para a molécula do antibiótico de enrofloxacina, assim como para Fernandes et al. (2009), e também para os seguintes antimicrobianos, a ciprofloxacina e a gentamicina, os quais apresentaram consecutivamente, $20 \mathrm{~mm}, 32 \mathrm{~mm}$ e 19 $\mathrm{mm}$ de halos de inibição do crescimento bacteriano.

Com relação ao perfil de sensibilidade antimicrobiana dos quatro óleos essenciais testados ante a cepas de Pseudomonas aeruginosa, está demonstrado conforme apresentado na Tabela 1. 
Tabela 1 - Tamanho do halo de inibição de crescimento da Pseudomonas aeruginosa em relação aos óleos essenciais de lavanda e manjericão

\begin{tabular}{l|l|l|l}
\hline & \multicolumn{3}{|c}{ TAMANHAO HALO DE } \\
& \multicolumn{3}{|c}{ INIBIÇÃ̃ } \\
\hline \multicolumn{1}{c|}{ PLANTA } & TESTE 1 & TESTE 2 & TESTE 3 \\
\hline $\begin{array}{l}\text { Folha } \\
\text { Manjericăo }\end{array}$ & $14 \mathrm{~mm}$ & $12 \mathrm{~mm}$ & $12 \mathrm{~mm}$ \\
\hline Flor Manjericăo & $7 \mathrm{~mm}$ & $7 \mathrm{~mm}$ & $7 \mathrm{~mm}$ \\
\hline Folha Lavanda & $8 \mathrm{~mm}$ & $8 \mathrm{~mm}$ & $6 \mathrm{~mm}$ \\
\hline Flor Lavanda & $9 \mathrm{~mm}$ & $7 \mathrm{~mm}$ & $6 \mathrm{~mm}$ \\
\hline
\end{tabular}

Fonte: Dados dos autores.

O óleo essencial de lavanda apresentou baixos níveis de sensibilidade no combate de cepas bacterianas de Pseudomonas aeruginosa, com uma média no tamanho do halo de inibição do crescimento da bactéria de 7,33 $\mathrm{mm}$ tanto para a folha quanto para a flor da planta, demonstrando uma atividade positiva, porém muito fraca (NASCIMENTO et al., 2000) para sua utilização como tratamento curativo em uma infecção na glândula mamária de bovinos leiteiros.

Acredita-se que esta atividade ineficiente do óleo obtido da lavanda tenha ocorrido em razão das variações dos constituintes presentes na planta dependendo das condições de manejo dessa, pois os constituintes dos óleos essenciais de uma mesma espécie de lavanda podem variar consideravelmente dependendo das condições edafoclimáticas de cultivo e do método de extração, e é essa variação que determina o seu potencial antibacteriano (CAVANAGH; WILKINSON, 2005).

Observamos que o óleo de lavanda testado neste trabalho não demonstrou eficiente ação antimicrobiana, fato atribuído às condições de coleta da planta, pois, segundo Paulus et al. (2013), quando a coleta da planta é realizada no mês de janeiro, período em que há maior quantidade de horas de luz solar por dia, o rendimento do óleo essencial presente na planta coletada é maior, o que agrega positivamente, aumentando seu potencial antimicrobiano.

Outro fator que tem sido observado é que as demais pesquisas apontam alto potencial para aplicação como agente antimicrobiano deste óleo para outras espécies bacterianas, conforme observado em estudo desenvolvido por Silveira et al. (2012). O óleo essencial de lavanda destacou-se pela atividade inibitória contra a Escherichia coli e Salmonella typhimurium, e, para Martucci et al. (2015), o óleo essencial obtido da folha demonstrou atividade sobre cepas de Staphylococcus aureus e Escherichia coli. Por outro lado, este produto natural demonstra uma atividade antifúngica mais potente, segundo Zuzarte et al. (2012), a qual se deve à presença de elevadas quantidades de carvacrol no óleo da planta.

Já com relação ao perfil de sensibilidade do óleo de manjericão para a $P$. aeruginosa, este apresentou resultados melhores quando comparado aos da lavanda. O óleo das mesmas plantas de manjericão, porém, sofreu variação quanto ao seu potencial antimicrobiano quando testado o óleo extraído de duas partes diferentes da planta, da flor e da folha, quando um deles (folha) apresentou resultado satisfatório e outro (flor) insatisfatório. O óleo essencial da flor do manjericão foi o produto que apresentou o pior resultado, com uma média de $7 \mathrm{~mm}$ no tamanho do halo de inibição nos três testes laboratoriais, o que demonstra sua inatividade como agente antimicrobiano no combate de cepas desta espécie bacteriana (NASCIMENTO et al., 2000).

O óleo essencial obtido da folha do manjericão foi o melhor produto das quatro amostras testadas. Este óleo apresentou a maior atividade inibitória, com uma média de 12,7 mm no tamanho dos halos de inibição de crescimento bacteriano.

Os resultados obtidos com os testes realizados com o manjericão demonstraram resultado positivo, com um potencial antimicrobiano elevado, havendo na literatura uma variedade de pesquisas que apontam resultados otimistas a este óleo em particular. Uma pesquisa verificou a presença do composto linalol no óleo da planta de manjericão, sem distinção quanto à parte da planta, composto considerado responsável pela eficiente atividade antimicrobiana do óleo a diversas espécies bacterianas, como para o Staphylococcus aureus, Bacillus subtilis, Escherichia coli e Aspergillus niger (HUSSAIN et al., 2008). Também para o Bacillus cereus, Bacillus subtilis, Pseudomonas aeruginosa, Listeria monocytogenes, Escherichia coli, Staphylococcus aureus, dentre outras bactérias (HUSSAIN et al., 2008; NEDOROSTOVA et al., 2009). Ainda, apresentou atividade antifúngica, inibindo o crescimento da Candida albicans, conforme Almeida et al. (2011), confirmando que o óleo essencial extraído do manjericão possui um potencial efetivo de atuar como agente antimicrobiano.

No óleo de Ocimum basilicum, já foram identificados 13 componentes, sendo $71,88 \%$ de linalol e 13,66\% de geraniol (AQUINO et al., 2010). Pesquisadores, como Hussain et al. (2008), encontraram teores de linalol no óleo de manjericão variando entre $54,9 \%$ 
e $60,6 \%$. Acreditando-se que a atividade antibacteriana deste óleo essencial se deva, principalmente, à presença deste composto.

A eficiente ação antimicrobiana dos óleos essenciais, em geral, também tem sido comprovada e apontada por outras investigações, representadas por meio de alta suscetibilidade de bactérias Gram positivas e negativas aos óleos (MACHADO; JUNIOR, 2011).

Dentro deste contexto em que os óleos essenciais são uma alternativa natural para o combate e o controle microbiológico, e possuem grande potencial de utilização, como antimicrobiano (REIS et al., 2020), surge outra questão importante relacionada à sua caraterística anti-inflamatória, capaz de inibir radicais livres e ativar agentes anti-inflamatórios, o que promove redução nos danos oxidativos aos tecidos corporais e causa redução da inflamação (STEVANOVIC et al., 2018; SILVA et al., 2019).

Dentro desta grande expectativa da utilização de óleos essenciais para o tratamento de mastites, em substituição ao uso de antibióticos, surge um importante benefício: o fato de evitar a ingestão de produtos lácteos contendo resíduos de antibióticos, o que reduz os riscos à saúde pública (PEREIRA et al., 2018), e também dificulta o processo de aquisição de resistência bacteriana (FERRO; MOURA; GERON, 2016).

Novas possibilidades de tratamento e prevenção de diversas enfermidades estão sendo buscadas por pesquisadores, visando o combate da resistência dos microrganismos a produtos, como os antibióticos. Neste contexto surge o óleo essencial, uma substância complexa, que pode atingir, ao mesmo tempo, diferentes alvos, farmacológicos ou conceituais, por obter respostas de alvos espalhados por todo o organismo, usufruindo de mudanças fisiológicas, tornando a utilização de óleos essenciais como uma alternativa de tratamento competente, além da vantagem de toda biodiversidade disponível em um país como o Brasil, o que favorece a obtenção das plantas para a extração dos óleos. Ainda a questão do uso de um produto natural que representa uma tendência atualmente, ao se tentar diminuir a utilização de substâncias químicas cumulativas e de suas reações adversas (MACHADO; JUNIOR, 2011).

\section{CONSIDERAÇÕES FINAIS}

Com relação à Pseudomonas aeruginosa, o óleo essencial que apresentou ação mais efetiva no combate ao microrganismo foi da folha do manjericão; os demais óleos testados não apresentaram resultados significativos.
Com tais resultados, é possível enfatizar a grande importância da utilização de alternativas importantes para o combate de bactérias causadoras de mastites, por meio da utilização de óleos essenciais extraídos de partes de plantas, como da flor e da folha da lavanda e do manjericão.

Sugere-se que o óleo essencial da folha do manjericão possa ser uma fonte de compostos com potencial terapêutico no combate à bactéria patogênica Pseudomonas aeruginosa. Recomenda-se a utilização do óleo como uma alternativa para o tratamento de mastites em bovinos leiteiros.

São necessários mais estudos, aliando a capacidade antimicrobiana do produto e a melhor via de administração para o tratamento de mastites. Além disso, deve ser investigado quanto à possibilidade de toxicidade do produto à célula animal. Sobretudo, é preciso avaliar o sinergismo ou antagonismo dos óleos com a fisiologia animal, bem como do custo-benefício do seu uso e, assim, verificar o potencial emprego de um produto antimicrobiano à base de óleos essenciais para o tratamento de infecções na glândula mamária de bovinos leiteiros.

\section{REFERÊNCIAS}

ALMEIDA, L. D. F. D. et al. Screening da atividade antifúngica de Óleos Essenciais sobre Candida Albicans. Revista Brasileira de Ciências da Saúde, v. 14, n. 4, p. 51-56, 2011.

ALVES, L. F. O laboratório da flora medicinal: marco no estudo das plantas medicinais Brasileiras. Revistas Fitos, São Paulo, v. 1, n. 2, p. 30-40. 2005.

ANTUNES, R. M. P. et al. Atividade antimicrobiana "in vitro" e determinação da concentração inibitória mínina (CIM) de fitoconstituintes e produtos sintéticos sobre bactérias e fungos leveduriformes. Revista Brasileira de Farmacognosia, v. 16, n. 4, p. 517-524, 2006.

AQUINO, L. C. L. et al. Atividade antimicrobiana dos óleos essenciais de erva-cidreira e manjericão frente a bactérias de carnes bovinas. Alim. Nutr., Araraquara. v. 21, n. 4, p. 529-535, out./dez. 2010.

BANDONI, A. L.; CZEPACK, M. P. Os recursos vegetais aromáticos no Brasil. 1. ed. Vitória: Edufes - Editora da Universidade Federal do Espírito Santo, 2008.

CAVANAGH, H. M. A.; WILKINSON, J. M. Lavender essential oil: a review. Austr Infect Control, v. 10, n. 1, p. 35-37, 2005.

EMBRAPA. Empresa Brasileira de Pesquisa Agropecuária. Indicadores, tendências e oportunidades para quem vive no setor leiteiro. 2018. Disponível em: https://www.embrapa.br/busca-de-publicacoes/-/publicacao/1094149/ anuario-leite-2018-indicadores-tendencias-e-oportunidades-para-quem-vive-no-setor-leiteiro. Acesso em: 25 out. 2019. 
FARMACOPÉIA BRASILEIRA. 6. ed. 2019. Agência Nacional de Vigilância Sanitária. Disponível em: http://portal.anvisa. gov.br/documents/33832/259143/Volume+I+Pronto.pdf/4ffodfe8-8a1d-46b9-84f7-7fa9673e1ee1. Acesso em: 20 set. 2019.

FERNANDES, M. C. et al. Surto de mastite bovina causada por linhagens de Pseudomonas aeruginosa multirresistentes aos antimicrobianos. Arq. Bras. Med. Vet. Zootec., v. 61, n. 3, p. 745-748, 2009.

FERRO, M. M.; MOURA, D. C.; GERON, L. J. V. Óleos essenciais em dietas para bovinos: revisão. Revista de Ciências Agroambientais, v. 14, n. 2, p. 47-57, 2016.

FIGUEIREDO, E. A. P. et al. Pseudomonas aeruginosa: frequência de resistência a múltiplos fármacos e resistência cruzada entre antimicrobianos no Recife/PE. Revista Brasileira de Terapia Intensiva, v. 19, n. 4, p. 421-427, out./dez. 2007.

HUSSAIN, A. I. et al. Chemical composition, antioxidante and antimicrobial activities of basil (Ocimum basilicum) essential oils depends on seasonal variations. Food Chem., v. 108, p. 986-995, 2008.

KIRBY J. C.; BAUER, A. W. Manual para antibiograma, difusão em disco. Laborclin, v. 5, p. 19-24, 2011.

LOUREIRO, R. J.; ROQUE, F.; RODRIGUES, A. T.; HERDEIRO, M. T.; RAMALHEIRA, E. O uso de antibióticos e as resistências bacterianas: breves notas sobre a sua evolução. Revista Portuguesa de Saúde Pública, v. 34, n. 1, p. 77-84, 2016.

MACHADO, B. F. M. T.; JUNIOR, A. F. Óleos essenciais: aspectos gerais e usos em terapias naturais. Cad. acad., Tubarão, v. 3, n. 2, p. 105-127, 2011.

MARTUCCI, J. F. et al. A. Oregano and lavender essential oils as antioxidant and antimicrobial additives of biogenic gelatin films. Industrial Crops and Products, v. 71, p. 205-213, 2015.

MCVEY, D. S.; KENNEDY, M.; CHENGAPPA, M. M. Microbiologia Veterinária. 3. ed. Rio de Janeiro: Guanabara Koogan. 2017. p. 153-155. Cap. 19.

MEGID, J.; RIBEIRO, M. G.; PAES, A. C. Doenças infecciosas em animais de produção e de companhia. 1. ed. Rio de Janeiro: Roca, 2018. p. 223-235. Cap. 23.

NASCIMENTO, G. G. F. et al. Antibacterial activity of plant extracts and phytochemicals on antibiotic resistant bacteria. Brazilian Journal of Microbiology, v. 31, p. 247-256, 2000.

NEDOROSTOVA, L. et al. Antimicrobial properties of selected essential oils in vapour phase against foodborne bacteria. Food Control, v. 20, p. 157-160, 2009.

OSTROSKY, E. A. et al. Métodos para avaliação da atividade antimicrobiana e determinação da concentração mínima inibitória (CMI) de plantas medicinais. Revista Brasileira de Farmacognosia, v. 18, n. 2, p. 301-307, 2008.

PAULUS, D. et al. Teor e composição química de óleo essencial de cidró em função da sazonalidade e horário de colheita. Horticultura Brasileira, v. 31, p. 203-209, 2013.
PEREIRA, C. T. M. et al. Microbiology quality, detection of enterotoxin genes and antimicrobial resistance of Staphylococcus aureus isolated from milk and Coalho cheese. Semina: Ciências Agrárias, Londrina, v. 39, n. 5, p. 1.957-1.968, set./out. 2018.

REIS, J. B. et al. Avaliação da atividade antimicrobiana dos óleos essenciais contra patógenos alimentares. Braz. J. Hea. Rev., Curitiba, v. 3, n. 1, p. 342-363, 2020.

RODRIGUES, A. T.; HERDEIRO, M. T.; RAMALHEIRA, E. O uso de antibióticos e as resistências bacterianas: breves notas sobre a sua evolução. Revista Portuguesa de Saúde Pública, v. 34, n. 1, p. 77-84, jan./abr. 2016.

SANTOS, M. V.; FONSECA, L. F. L. Estratégias para controle de mastite e melhoria da qualidade do leite. São Paulo: Manole, 2007.

SILVA, B. K. et al. Uso de óleos essenciais em bovinos. Sinapse Múltipla, v. 8, n. 2, p. 230-234, 2019.

SILVEIRA, S. M. et al. Composição química e atividade antibacteriana dos óleos essenciais de Cymbopogon winterianus (citronela), Eucalyptus paniculata (eucalipto) e Lavandula angustifolia (lavanda). Revista do Instituto Adolfo Lutz, v. 71, n. 3, p. 471-480, 2012.

SHER, A. Antimicrobial activity of natural products from medicinal plants. Gomal. Journal of Medical Sciences, v. 7, n. 1, p. 72-79, 2009.

SPADACIO, C. et al. Medicinas alternativas e complementares: uma metassintese. Caderno de Saúde Pública, Rio de Janeiro, v. 26, n. 1, p. 7-13, 2010.

STEVANOVIC, Z. D. et al. Essential Oils as Feed Additives - Future Perspectives. Molecules, Belgrade, v. 23, n. 7, p. 1-20, jul. 2018.

TOZZETTI, D. S.; BATAIER, M. B. N.; ALMEIDA, L. R. Prevenção, controle e tratamento das mastites bovinas - revisão de literatura. Revista Científica Eletrônica de Medicina Veterinária, ano XI, n. 10, jan. 2008.

ZIMBRO, Mary Jo et al. (ed.). DIFCO \& BBL Manual. Manual of Microbiological Culture Media. 2. ed. Sparks, Maryland: Becton; Dickinson and Company, 2009. Disponível em: https://www.trios.cz/wp-content/uploads/sites/149/2016/08/DIFCO-A-BBL-MANUAL-2.pdf. Acessado em: 17 dez. 2019.

ZUZARTE, M. et al. Antifungal activity of phenolic-rich Lavandula multifida L. essential oil. European Journal of Clinical Microbiology \& Infectious Diseases, v. 31, n. 7, p. 1.3591.366, 2012. 